\title{
Can colour vision re-evolve? Variation in the X-linked opsin locus of cathemeral Azara's owl monkeys (Aotus azarae azarae)
}

\author{
N. I. Mundy ${ }^{1 *}$, N. C. Morningstar ${ }^{2}$, A. L. Baden ${ }^{2,3}$, E. Fernandez-Duque ${ }^{2,4,5}$, V. M. Dávalos ${ }^{5}$ and B. J. Bradley ${ }^{2,6^{*}}$
}

\begin{abstract}
Background: Do evolutionary specializations lead to evolutionary constraint? This appears plausible, particularly when specialization leads to loss of complex adaptations. In the owl monkey lineage, nocturnality clearly arose from a diurnal ancestor. This behavioural shift was accompanied by morphological changes in the eye and orbit and complete loss of colour vision via missense mutations in the gene encoding the short-wave sensitive visual pigment (SWS opsin). Interestingly, at least one subspecies of owl monkey, Azara's owl monkey (Aotus azarae azarae), has regained activity in daylight. Given that all primate species that are active in daylight, including primarily diurnal species and species that are active during both day and night, have at least dichromatic colour vision, it seems reasonable to propose that dichromacy would be adaptive in A. a. azarae. With a disabled SWS opsin, the main avenue available for Azara's owl monkeys to re-evolve colour vision is via a polymorphism in the intact X-linked opsin locus, which commonly occurs in other New World monkeys. To examine this possibility we assayed variation in the X-linked opsin of $A$. a. azarae, focusing on the three exons (3, 4 and 5$)$ that control spectral sensitivity.

Results: We found low opsin genetic variation on a population level, and no differences at the three main sites that lead to variation in spectral sensitivity in the opsins of other New World monkeys. Two rare alleles with single amino acid variants are segregating in the population, but previous functional studies indicate that these are unlikely to affect spectral sensitivity.

Conclusions: Genetic constraint on the re-evolution of colour vision is likely operating in Azara's owl monkey, which may affect the niche that this subspecies is able to occupy.
\end{abstract}

Keywords: Aotus, Owl monkey, Platyrrhine, Colour vision, Activity pattern

\section{Background}

In evolutionary biology, Dollo's Law proposes that complex adaptations cannot be reacquired easily once lost [1]. This can therefore lead to a genetic constraint on adaptation if the environment subsequently changes. Although the hypothesis has received much attention and theoretical support, there are few cases in which it has been empirically documented [2]. Owl monkeys (Aotus) are the only nocturnal group of anthropoid primates, and they have a suite of visual adaptations for a

\footnotetext{
* Correspondence: nim21@cam.ac.uk; bradleyjbrenda@gwu.edu 'Department of Zoology, University of Cambridge, Cambridge, UK ${ }^{2}$ Department of Anthropology, Yale University, New Haven, CT, USA Full list of author information is available at the end of the article
}

nocturnal lifestyle including a large eye and orbit size, and a high retinal rod to cone ratio [3]. In common with several other nocturnal primate lineages, owl monkeys lost the capacity for colour vision, having evolved to become monochromatic (completely colour-blind) from a dichromatic ancestor [4]. This occurred as a result of deleterious mutations in the autosomal short wavelength sensitive (SW) opsin locus, leaving a single intact middle wavelength sensitive (MW) opsin on the X chromosome [5].

Unlike other owl monkey species which are strictly nocturnal, the Azara's owl monkeys (A. a. azarae) of Argentina and Paraguay are cathemeral [6], showing considerable amounts of activity both during the dark and light phases of the 24-h cycle [7]. Most of their 
activity is concentrated at times of limited luminosity (dawn, dusk, and night), but daytime (0900-1800hs) activity is present year round, reaching a maximum (31\%) during the cold winter months and a minimum (13\%) in the summer [7].

All other primate species that are active in daylight, including both primarily diurnal species and species that exhibit substantial periods of activity during both day and night, have either dichromatic or trichromatic colour vision $[8,9]$ suggesting a pervasive adaptive advantage for colour vision at high luminance levels in primates. Hence, it is hypothesized that the partially diurnal activity pattern of Azara's owl monkeys has created a selective pressure for dichromacy leading to the re-evolution of adaptive colour vision. One potential mutational mechanism for colour vision to re-evolve would be for the SW opsin to regain functionality, but this has not occurred [10]. A second possibility is that a novel spectrally sensitive allele could evolve at the Xlinked MW opsin locus. This change would lead to heterozygous females having two functional opsin alleles, and likely a form of dichromacy, whereas homozygous females and hemizygous males would remain monochromatic. This situation would be analogous to the X-linked opsin polymorphism in most other New World monkeys, except that in these species the SW locus is intact resulting in dichromatic males and heterozygous trichromatic females [8]. Mutations impacting X-linked opsin sensitivity have occurred repeatedly along multiple lineages during primate evolution [11], so it would not be surprising if Azara's owl monkeys exhibited such a polymorphism. Here we examine this hypothesis in a wild population of Azara's owl monkeys by assaying sequence variation in the regions of the MW opsin gene that determine spectral sensitivity.

\section{Results and discussion}

We obtained the full coding sequence of exons 3-5 of the $\mathrm{X}$-linked opsin gene for 20 females. There was no amino acid variation at the three key sites (site 180 in exon 3 and sites 277 and 285 in exon 5) that are responsible for the majority of variation in maximal spectral sensitivity $\left(\lambda_{\max }\right)$ in primates (Table 1$)$. These sites are identical to those in the conspecific A. a. boliviensis,

Table 1 X-linked opsin variation in AzaraZs owl monkeys (Aotus a. azarae)

\begin{tabular}{|c|c|c|c|c|c|c|c|c|c|c|}
\hline & & \multirow[b]{2}{*}{$N$} & \multicolumn{2}{|c|}{ Ex 3} & \multicolumn{3}{|c|}{ Exon 4} & \multicolumn{3}{|c|}{ Exon 5} \\
\hline & & & 180 & 229 & 213 & 233 & 277 & 285 & 294 & 312 \\
\hline \multirow[t]{2}{*}{ A. a. azarae } & Allele 1 & 38 & A & I & Y & $S$ & Y & A & $\mathrm{N}$ & $\mathrm{K}$ \\
\hline & Allele 2 & 2 & A & । & Y & S & Y & A & D & $\mathrm{R}$ \\
\hline A. a. boliviensis & & & A & । & Y & S & Y & A & N & K \\
\hline
\end{tabular}

Variable sites and sites potentially affecting spectral sensitivity are shown in single letter amino acid code, with the three key sites in bold whose MW opsin has an experimentally determined $\lambda_{\max }$ of $539 \mathrm{~nm}$ [12]. Two rare amino acid variants, D294N and K312R, both in exon 5, were present as heterozygous variants in two individuals (frequency of both variants $5 \%$ ), and are likely linked. K312R is a conservative mutation that is not at a site that affects spectral sensitivity. D294N is interesting because it affects spectral sensitivity (reduction in $\lambda_{\max }$ ) in spider monkeys, but only in the presence of a second variant, Y213D [13]. As Y213D is absent in Azara's owl monkey it is unlikely that D294N affects spectral sensitivity in this taxon. While the sample size of $40 \mathrm{X}$ chromosomes was modest, it would have easily been large enough to detect allelic variation at the X-linked opsin locus in the majority of New World monkeys, where the frequency of individual alleles is typically $15-50 \%$ (e.g. see [14]).

Thus, overall we found little evidence of functional variation in the X-linked opsin of Azara's owl monkey which would lead to dichromatism and the reemergence of colour vision in heterozygous females. Hence, the two main routes to reacquisition of colour vision, which involve the only opsins expressed in retinal cones in primates - regeneration of the SWS opsin [10], and functional variation in the X-linked opsin (this study) - have not occurred. At intermediate (mesopic) light conditions, rhodopsin expressed in rods may play a role in colour vision $[4,15-17]$, and this would be interesting to explore in the future, particularly since the high rod density in owl monkeys means that their mesopic range likely extends to higher light levels than in diurnal anthropoid primates. However, rhodopsin cannot contribute to colour vision under the daylight (photopic) conditions which Azara's owl monkeys experience. Another class of opsins, melanopsins, are expressed in some retinal ganglion cells and function in entraining circadian rhythms and in sensing overall luminance, but it is not yet clear whether they are able to contribute to colour vision $[18,19]$.

Given the high rod to cone density in the retinas of owl monkeys, it is worth considering whether this is a stronger constraint on the re-evolution of colour vision than the regeneration of relevant opsin variation. For example, in mice that were genetically engineered to express an extra human LW opsin, behavioural evidence for colour vision was rare [20]. However, certain lemurs have behaviourally demonstrated colour vision that relies on cone densities that are similar to those found in Aotus [21, 22], arguing against a strong constraint based on cone density. Also, it remains to be determined whether there has been any change in cone abundance in $A$. a. azarae. Another possibility is that spectral separation of a novel X-linked opsin may not be sufficient to provide useful colour vision. Human tritanopes are analogous dichromats that do retain useful colour vision 
with a $\sim 30 \mathrm{~nm}$ separation among the MW and LW pigments [23], although smaller spectral separations would be possible in Aotus.

Comparative data strongly suggest that colour vision would be adaptive in Azara's owl monkey; given that they are primarily frugivorous [24], colour vision would likely aid in food selection. All primates that show substantial activity during the daytime, whether strictly diurnal species or species that are active both at day at night [25] have some form of colour vision (dichromatic or trichromatic) $[8,9,11]$. In contrast, all monochromatic primates apart from Azara's owl monkey, including other owl monkeys, lorisoids and some cheirogaleid lemurs, are strictly nocturnal. The adaptive advantage of dichromacy over monochromacy for daytime activity is poorly studied, particularly in comparison to advantages of trichromacy over dichromacy, and warrants further investigation.

$\mathrm{X}$-linked opsin changes impacting colour vision have evolved independently in several primate lineages [11], but the time scale and historical contingency of such mutations is unclear. While Azara's owl monkeys may have diverged from other Aotus lineages up to a few million years ago [26], there is considerable uncertainty over when the characteristic periods of diurnal activity evolved in A. a. azarae. Azara's owl monkeys are found exclusively in the seasonally dry forests of the South American Gran Chaco and a recent evaluation of mtDNA diversity in this taxon concluded that the expansion into this area may have been relatively recent, occurring after climatic and geographic processes drained the southernmost Chacoan forests and flatlands of water some 5,000-7,000 years ago [26]. With a mutational target in the X-linked opsin locus of just three major sites to alter spectral sensitivity, and a nuclear mutation rate on the order of $0.5 \times 10^{-9} /$ site/year in primates [27], the expected time to acquisition of dichromacy would be long.

In some cases, re-evolution of complex structures has occurred after many millions of years (e.g., the reacquisition of mandibular teeth in frogs [28]). A plausible explanation is that in these cases the developmental pathways underlying the traits that re-evolve are conserved with other structures that are retained during evolution. Hence the functional protein sequences remain and re-evolution of the trait requires mutations restoring gene expression patterns. In contrast, the visual pigments underlying colour vision in vertebrates do not have pleiotropic functions elsewhere in the body, and this has the effect of making restoration of colour vision difficult. This is because loss of colour vision can be accompanied by loss-of- function mutations in the coding sequence of opsin genes, as occurred in the SWS opsin gene in the Aotus lineage, and the SWS pseudogene can then further degenerate by accumulation of extra deleterious mutations. Regeneration of colour vision via the SWS opsin then becomes very unlikely and instead precise mutations in the MW opsin must occur.

\section{Conclusions}

A genetic constraint on the re-evolution of colour vision appears to be present in Azara's owl monkey in the sense that mutations that could restore colour vision have not yet occurred. The absence of colour vision could potentially influence the niche these monkeys are able to occupy. More broadly, the genus Aotus offers an excellent opportunity to examine the phenotypic and genetic mechanisms behind adaptations to gross changes in activity pattern, which is a key ecological trait.

\section{Methods \\ Samples}

DNA was derived from blood samples collected from 20 wild females of Aotus azarae azarae (17 from 16 different social groups and 3 from solitary individuals) as part of the Owl Monkey Project (Proyecto Mirikiná) in the Formosa Province of Argentina [29]. DNA was isolated using QIAamp purification kits (Qiagen). All protocols adhered to the laws of Argentina, the United States and the United Kingdom, and were approved by respective animal care and use committees (University of Pennsylvania: IACUC\#2010-801089; Yale University: IACUC\#201011378).

\section{Amplification and sequencing}

Since Y chromosome opsin pseudogenes are present in Aotus [30], we eliminated the possibility of these interfering with genotyping by focusing on females. Samples were amplified at exons 3, 4, and 5 of the X-linked opsin using primers designed from an Aotus azarae boliviensis reference sequence (GenBank: AB081277.2). $24 \mu \mathrm{l}$ PCR reactions consisted of: $1.0 \mu \mathrm{l}$ template, $10 \mu \mathrm{M}$ of each primer and $12.5 \mu \mathrm{l}$ Qiagen HotStarTaq Master Mix. Amplification conditions were as follows: $15 \mathrm{~m}$ initial denaturation at $95{ }^{\circ} \mathrm{C} ; 30-35$ cycles of 30 s at $94{ }^{\circ} \mathrm{C}, 40 \mathrm{~s}$ at $61{ }^{\circ} \mathrm{C}, 60 \mathrm{~s}$ at $72{ }^{\circ} \mathrm{C}$; and a $7 \mathrm{~m}$ final extension at $72{ }^{\circ} \mathrm{C}$. Products were sequenced on both strands at the Yale DNA Analysis Facility (ABI3730). Sequence files were aligned and translated using Geneious (Biomatters).

\section{Availability of supporting data}

Novel DNA sequences have been deposited in Genbank (Accession KU728173).

Competing interests

The authors declare that they have no competing interests. 


\section{Authors' contributions}

NIM, BJB and EF-D designed the study; BJB, EFD-D, NCM, VD and ALB generated biological samples and data; BJB and NIM analysed the results; NIM, BJB and EF-D wrote the manuscript. All authors read and approved the final manuscript.

\section{Acknowledgments}

We thank P. Babb and T. Schurr for sharing extracted DNA samples, G. Aronsen for lab assistance and M. Rotundo and C. Juárez for their field work that made the study possible. We thank four anonymous reviewers for helpful comments on the manuscript. We thank the Yale College Dean's Research Fellowship in the Sciences, Paul K. and Evalyn Elizabeth Cook Richter Scholarship Fund, Wenner-Gren Foundation, L.S.B. Leakey Foundation, National Geographic Society, National Science Foundation (BCS-640 0621020, BCS-837921, BCS-904867, BCS-924352), National Institutes of Aging (P30 AG012836-19), the University of Pennsylvania Research Foundation and the Zoological Society of San Diego for supporting this project.

\section{Author details}

'Department of Zoology, University of Cambridge, Cambridge, UK. ${ }^{2}$ Department of Anthropology, Yale University, New Haven, CT, USA. ${ }^{3}$ Department of Anthropology, Hunter College of the City University of New York, New York, USA. ${ }^{4}$ Department of Anthropology, University of Pennsylvania, Pennsylvania, USA. ${ }^{5}$ Facultad de Recursos Naturales, Universidad Nacional de Formosa, Formosa, Argentina. ${ }^{6}$ Center for the Advanced Study of Human Paleobiology, The George Washington University, Washington, DC, USA.

\section{Received: 29 October 2015 Accepted: 4 February 2016}

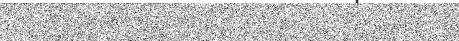

\section{References}

1. Gould SJ. Dollo on Dollo's law: irreversibility and the status of evolutionary laws. J History Biol. 1970;3:189-212.

2. Collin R, Miglietta MP. Reversing opinions on Dollo's Law. Trends Ecol Evol. 2006:23:602-9

3. Dyer MA, Martins R, da Silva FM, Muniz JAPC, Silveira LCL, Cepko CL, et al. Developmental sources of conservation and variation in the evolution of the primate eye. Proc Natl Acad Sci U S A. 2009;106:8963-898.

4. Jacobs GH, Deegan JF, Neitz J, Crognale MA, Neitz M. Photopigments and color vision in the nocturnal monkey, Aotus. Vision Res. 1993;33:1773-83.

5. Jacobs GH, Neitz M, Neitz J. Mutations in S-cone pigment genes and the absence of colour vision in two species of nocturnal primate. Proc Roy Soc B. 1996;263:705-10.

6. Tattersall I. Cathemeral activity in primates: a definition. Folia Primatol. 1987; 49:200-2.

7. Erkert HG, Fernandez-Duque E, Rotundo M, Scheideler A. Seasonal variation of temporal niche in wild owl monkeys (Aotus azarae azarae) of the Argentinian Chaco: a matter of masking? Chronobiol Int. 2012;29:702-14.

8. Surridge AK, Osorio D, Mundy NI. Evolution and selection of trichromatic vision in primates. Trends Ecol Evol. 2003;18:198-205.

9. Veilleux CC, Bolnick DA. Opsin gene polymorphism predicts trichromacy in a cathemeral lemur. Am J Primatol. 2009;71:86-90.

10. Levenson DH, Fernandez-Duque E, Evans S, Jacobs GH. Mutational changes in S-cone opsin genes common to both nocturnal and cathemeral Aotus monkeys. Am J Primatol. 2007:69:757-65.

11. Jacobs GH. Primate photopigments and primate color vision. Proc Natl Acad Sci U S A. 1996:23:577-81

12. Hiramatsu C, Radlwimmer FB, Yokoyama S, Kawamura S. Mutagenesis and reconstitution of middle-to-long-wave-sensitive visual pigments of New World monkeys for testing the tuning effect of residues at sites 229 and 233. Vision Res. 2004;44:2225-31.

13. Matsumoto $Y$ et al. Evolutionary renovation of $L / M$ opsin polymorphism confers a fruit discrimination advantage to ateline New World monkeys. Mol Ecol. 2014;23:1799-812

14. Surridge AK, Suárez SS, Buchanan Smith HM, Smith AC Mundy NI. Colour vision pigment frequencies in wild tamarins (Saguinus spp.). Am J Primatol. 2005;67:463-70.

15. Cao D, Pokorny J, Smith VC, Zele AJ. Rod contributions to color perception: linear with rod contrast. Vision Res. 2008;48:2586-92.
16. Field GD, Greschner M, Gauthier JL, Rangel C, Shlens J, Sher A, et al. Highsensitivity rod photoreceptor input to the blue-yellow color opponent pathway in macaque retina. Nat Neurosci. 2009;12:1159-64.

17. Freitag FB, Pessoa DMA. Effect of luminosity on color discrimination of dichromatic marmosets (Callithrix jacchus). J Opt Soc Am A. 2012;29:A216-22

18. Horiguchi $\mathrm{H}$, Winawer J, Dougherty RF. Wandell BA Human trichromacy revisited. Proc Natl Acad Sci U S A. 2013;110:E260-9.

19. Allen $A E$, Storchi $R$, Martial FP, Petersen RS, Montemurro MA, Brown TM, et al. Melanopsin-driven light adaptation in mouse vision. Curr Biol. 2014;24: 2481-90.

20. Jacobs GH, Williams GA, Cahill H, Nathans J. Emergence of novel color vision in mice engineered to express a human cone photopigment Science. 2007:315:1723-5.

21. Blakeslee B, Jacobs GH. Color vision in the ring-tailed lemur (Lemur catta). Brain Behav Evol. 1985;26:154-66.

22. Jacobs GH, Deegan JF. Photopigments underlying color vision in ringtail lemurs (Lemur catta) and brown lemurs (Eulemur fulvus). Am J Primatol. 1993;30:243-56

23. Stockman A, Sharpe LT. Tritanopic color matches and the middle-and longwavelength-sensitive cone spectral sensitivities. Vision Res. 2000;40:1739-50.

24. Fernandez-Duque, E. Social monogamy in wild owl monkeys (Aotus azarai azarai) of Argentina: the potential influences of resource distribution, ranging patterns and competition. Am J Primatol 2015; DOl: 10.1002/ajp. 22397 (In press).

25. Curtis $D$, Rasmussen MA. The evolution of cathemerality in primates and other mammals: A comparative and chronoecological approach. Folia Primatol. 2006;77:178-93.

26. Babb PL, Fernandez-Duque E, Baiduc CA, Gagneux P, Evans S, Schurr TG. mtDNA diversity in Azara's owl monkeys (Aotus azarai azarai) of the Argentinean Chaco. Am J Phys Anthr. 2011;146:209-24.

27. Scally A, Durbin RA. Revising the human mutation rate: implications for understanding human evolution. Nat Rev Genet. 2012;13:745-53.

28. Wiens JJ. Re-evolution of lost mandibular teeth in frogs after more than 200 million years, and re-evaluating Dollo's Law. Evolution. 2011;65:1283-96.

29. Fernandez-Duque E, De la Iglesia H, Erkert HG. Moonstruck primates: owl monkeys (Aotus) need moonlight for nocturnal activity in their natural environment. PLoS One. 2010:9:e12572.

30. Kawamura S, Takenaka N, Hiramatsu C, Hirai M, Takenaka O. Y-chromosomal red-green opsin genes of nocturnal New World monkey. FEBS Lett. 2002; $530: 70-2$

\section{Submit your next manuscript to BioMed Central and we will help you at every step:}

- We accept pre-submission inquiries

- Our selector tool helps you to find the most relevant journal

- We provide round the clock customer support

- Convenient online submission

- Thorough peer review

- Inclusion in PubMed and all major indexing services

- Maximum visibility for your research

Submit your manuscript at www.biomedcentral.com/submit
C Biomed Central 